MAGNANR]

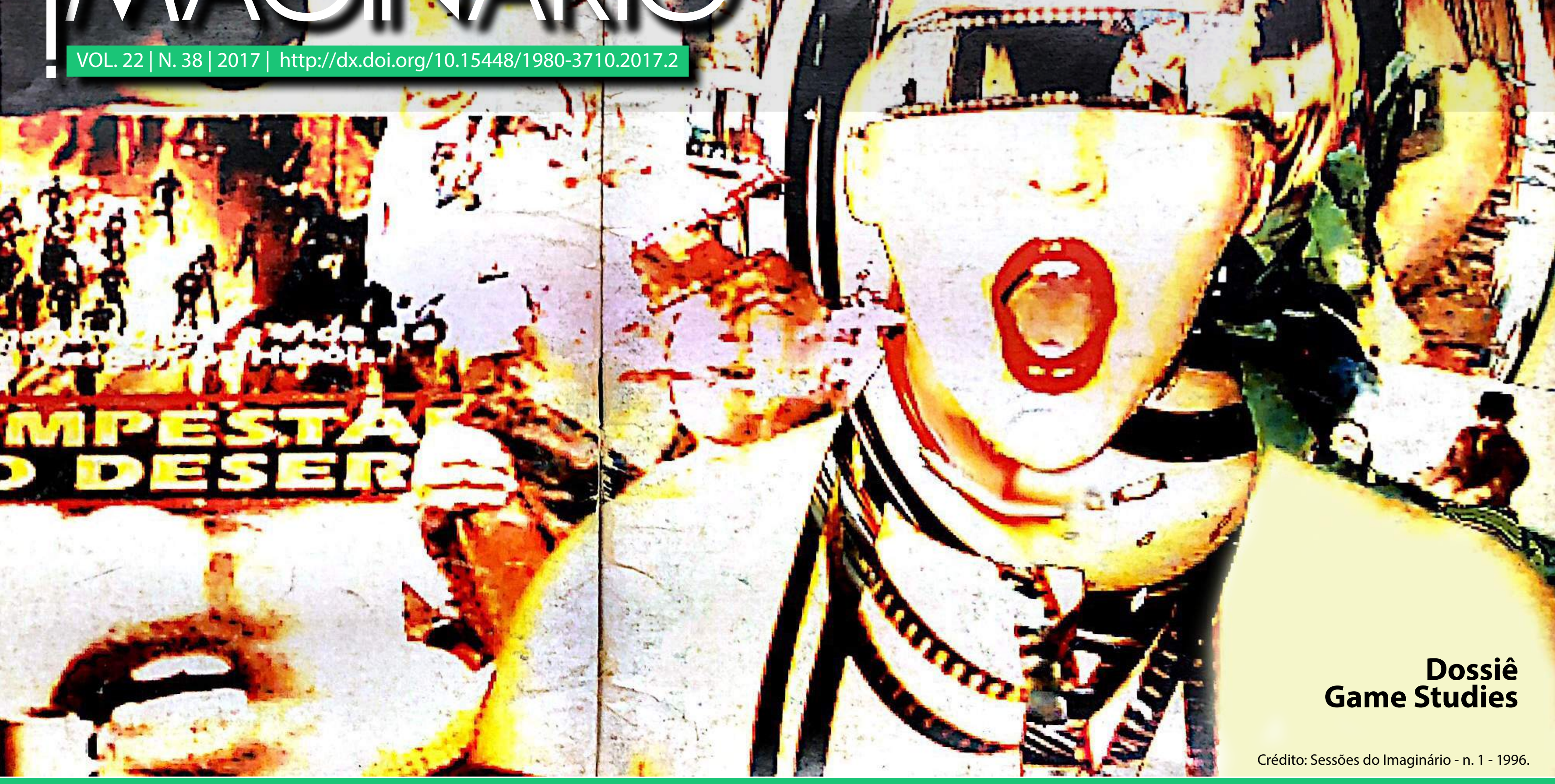

A estética do imaginário no cinema

Demian Garcia e André A. Medeiros P. 94
Materialidades fílmicas, magia e montagem

Ednei de Genaro
Videogames, transgressão e criatividade no Brasil Emmanoel Ferreira

P. 72 


\section{A guerra dos clones: transgressão e criatividade na aurora dos videogames no Brasil ${ }^{1}$}

\author{
The Clone Wars: transgression and \\ creativity at the dawn of video \\ games in Brazil
}

\section{Resumo}

Este artigo analisa a importância das práticas de clonagem de consoles de videogames e microcomputadores nos anos 1980 no Brasil, além da pirataria de jogos/software, na erupção de um mercado incipiente de videogames no país, no início da década de 1980. A principal hipótese deste trabalho é que tais práticas de clonagem e pirataria, amplamente levadas a cabo por pequenas e grandes empresas brasileiras durante toda a década de 1980 e transgredindo e subvertendo todas as regras, leis e normas vigentes à época, acabaram por colocar o Brasil em quase pé de igualdade com países pioneiros no mercado de videogames, como Japão e Estados Unidos, no que tange ao consumo de tal mídia. Ademais, o trabalho busca demonstrar que sem estas práticas o país se atrasaria ao menos em uma década para adentrar no mercado mundial de videogames.

\section{Palavras-chave}

Clonagem; pirataria; Atari; NES; MSX.

\section{Abstract}

This article analyzes the importance of the cloning practices of video game consoles and microcomputers in the 1980s in Brazil, in addition to game / software piracy, in the eruption of an incipient video game market in the country in the early 1980s. of this work is that such practices of cloning and piracy, largely carried out by small and large Brazilian companies throughout the 1980s and transgressing and subverting all the rules, laws and norms in force at the time, ended up putting Brazil almost on foot of equality with pioneering countries in the videogames market, such as Japan and the United States, with regard to the consumption of such media. In addition, the work seeks to demonstrate that without these practices the country would be delayed in at least a decade to enter the world market of video games.

\section{Keywords}

Cloning; piracy; Atari; NES; MSX.

72 PORTO ALEGRE | v. 22 | n. 38 | 2017 | p. 72-84

|MAGINAR' 


\section{Introdução}

É razoável afirmar que a disseminação dos videogames no Brasil começou com o lançamento do Atari 2600 e seus muitos clones no ano de 1983 (Chiado, 2013). Esta disseminação primeira teria sido responsável pelo começo de um incipiente mercado de games no país. As origens e o desenvolvimento de tal mercado tiveram aspectos particulares no Brasil, especialmente por causa das práticas de clonagem e pirataria que ocorreram naquela época. Essas práticas não aconteceram por acaso, mas foram, antes de tudo, impulsionadas pela Política de Reserva de Mercado, em vigor no final da década de 1970 e durante toda a década de 1980 no Brasil.

Nesse sentido, e dentro das perspectivas da "arqueologia da mídia" (Huhtamo, Parikka, 2011; Zielinski, 2006) e dos "estudos de plataforma" (Montfort, Bogost, 2009), este artigo tem por objetivo analisar a importância das práticas de clonagem de consoles de videogames e microcomputadores e também da pirataria de jogos/software na erupção de um mercado incipiente de videogames no Brasil, no início da década de 1980. A principal hipótese deste trabalho é que tais práticas de clonagem e pirataria, amplamente levadas a cabo por pequenas e grandes empresas brasileiras durante toda a década de 1980 e transgredindo e subvertendo todas as regras, leis e normas vigentes à época, acabaram por colocar o Brasil em quase pé de igualdade com países pioneiros no mercado de videogames, como Japão e Estados Unidos, no que tange ao consumo de tal mídia. Ademais, busca demonstrar que sem estas práticas o país se atrasaria ao menos em uma década para adentrar no mercado mundial de videogames.
Assim, na mesma perspectiva dos autores acima mencionados, acredito que o estudo de momentos-chave historicamente construídos/desenvolvidos de um medium particular - com base em contextos sociais, econômicos e culturais específicos - pode contribuir para a compreensão das diversas práticas sociais, econômicas e culturais resultantes da interação das pessoas com esses mesmos media. Para o escopo deste trabalho, focarei meu estudo na análise de clones de duas plataformas de consoles e uma plataforma de computador, todas lançadas no Brasil na década de 1980: as plataformas dos consoles Atari 2600 e Nintendo Entertainment System (NES), e a plataforma do computador/sistema MSX. Esta análise tem por intuito contribuir para uma melhor compreensão do complexo contexto dos videogames no Brasil e como ele se relaciona com o contexto dos videogames em outras partes do mundo.

\section{O cenário político e econômico brasilei- ro na década de 1980}

A década de 1980, muitas vezes chamada de "a década perdida", foi um período na política e na economia brasileira marcado por uma grande recessão econômica e por uma grave turbulência política. Em relação à política, no início da década de 1980, o país era governado por um governo militar, que assumiu o controle em 1964. Em relação à economia, durante a mesma década, o Brasil passava por um dos seus mais difíceis períodos econômicos do século XX. As taxas de inflação chegaram a atingir o patamar de $200 \%$ ao ano em 1983 (Oliveira, 2005). O país estava em grande recessão econômica e os comerciantes estavam preocupados com as vendas de Natal daquele ano.

\section{A política de reserva de mercado}

Alguns anos antes, em 1977, o governo federal lançou uma política que tornava proibido - ou, como aconteceu na prática, ao menos muito difícil - às empresas brasileiras importar produtos eletrônicos - componentes e/ou dispositivos inteiros - de fabricantes estrangeiros. Esta política tinha por objetivo impulsionar a economia brasileira através do desenvolvimento de empresas nacionais de tecnologia. Esta "política de substituição de importações" deveria promover o know-how tecnológico brasileiro para que o país pudesse se tornar cada vez menos dependente de tecnologia estrangeira - especialmente dos EUA - marchando rumo ao seu próprio progresso. Também era proibido às empresas brasileiras enviar royalties a empresas estrangeiras (Marques, 2000). Nas palavras de Marques:

\begin{abstract}
[Durante a década de 1970], predominou, na comunidade acadêmica, a ideia de que os brasileiros deveriam fazer um investimento estratégico para superar a dependência tecnológica. Aplicada ao setor de informática, a ideia da dependência tecnológica traduzia-se em uma grande preocupação: se passasse a depender cada vez mais de computadores e não soubesse fazê-los, então o Brasil se veria na condição de pagar qualquer que fosse o preço fixado por aqueles poucos países que sabiam fazer os computadores (Marques, 2000, p. 96).
\end{abstract}

Fica bastante claro que a Reserva de Mercado tinha, ao menos em princípio, uma boa intenção quanto à independência econômica e tecnológica brasileira. No entanto, como alguns autores argumentam (lkeha- 
ra, 1997), a política acabou por não alcançar seus objetivos. Além disso, a política também proibia que empresas estrangeiras de computadores se instalassem no Brasil. Assim, não era possível, por exemplo, que a Commodore ou a Apple ou a Atari abrissem uma filial no país e distribuíssem seus produtos - algo bastante comum nos dias de hoje.

Em 1984, a Política de Reserva de Mercado foi convertida na Lei Federal n. 7232 (outubro de 1984), conhecida como "Lei de Informática". A Reserva de Mercado foi revogada em outubro de 1991, quando o país estava passando pelo chamado "processo de abertura do mercado". Entre outras coisas, a Lei de Informática declarava:

Art. 4 - São instrumentos da Política Nacional de Informática:

I - o estímulo ao crescimento das atividades de informática de forma compatível com o desenvolvimento do país.

Art. 9 - Para assegurar adequados níveis de proteção às empresas nacionais, enquanto não estiverem consolidadas e aptas a competir no mercado internacional [...], o Poder Executivo adotará restrições [...] à produção, operação, comercialização, e importação de bens e serviços técnicos de informática ${ }^{3}$.

Deste modo, a Reserva de Mercado, agora convertida naquilo que foi chamado de Lei de Informática, impedia que empresas brasileiras realizassem atividades econômicas que dependessem de tecnologia estrangeira, no intuito de promover o crescimento do desenvolvimento de produtos relacionados à tecnologia, a serem desenvolvidos no Brasil. Ainda no que tange à relação entre a Reserva de Mercado e o fomento de um mercado de videogames no Brasil, Marcus Chiado afirma: "A Reserva acabaria, como o desenrolar dos acontecimentos mostrou, por alavancar o lançamento dos primeiros sistemas de videogames e os primeiros cartuchos no Brasil" (Chiado, 2013, p. 23).

\section{A indústria de videogames no Brasil:}

\section{dos clones aos oficiais, e vice-versa}

Embora na América do Norte a indústria de videogames passasse por sua primeira "quebra", amplamente conhecida como o videogame crash de 1983, no Brasil as coisas corriam em outro ritmo. $O$ primeiro console de videogame a aparecer no mercado brasileiro foi o Telejogo, fabricado pela Philco-Ford e lançado em 1977. Este console doméstico, uma espécie de console ao estilo Pong, vinha com três jogos em sua memória (Paredão, Tênis e Futebol) e com dois paddles embutidos no próprio console. Dois anos depois, a mesma empresa lançou seu sucessor, o Telejogo 2, que acompanhava 10 jogos (Hóquei, Tênis, Paredão I, Paredão II, Basquete I, Basquete II, Futebol, Barreira, Tiro ao Alvo I, Tiro ao Alvo II); ao contrário de seu antecessor, esta versão vinha com dois joysticks que eram conectados permanentemente ao console. $\mathrm{O}$ design deste console foi muito mais próximo do design do console Atari 2600, exceto pelo fato de não ter um slot de cartucho, com um número limitado de jogos. O próximo passo no mercado de videogames no Brasil seria o lançamento de um dos consoles da segunda geração, e a escolha não poderia ter sido outra que não o Atari 2600 , devido ao seu sucesso no mercado norte-americano.
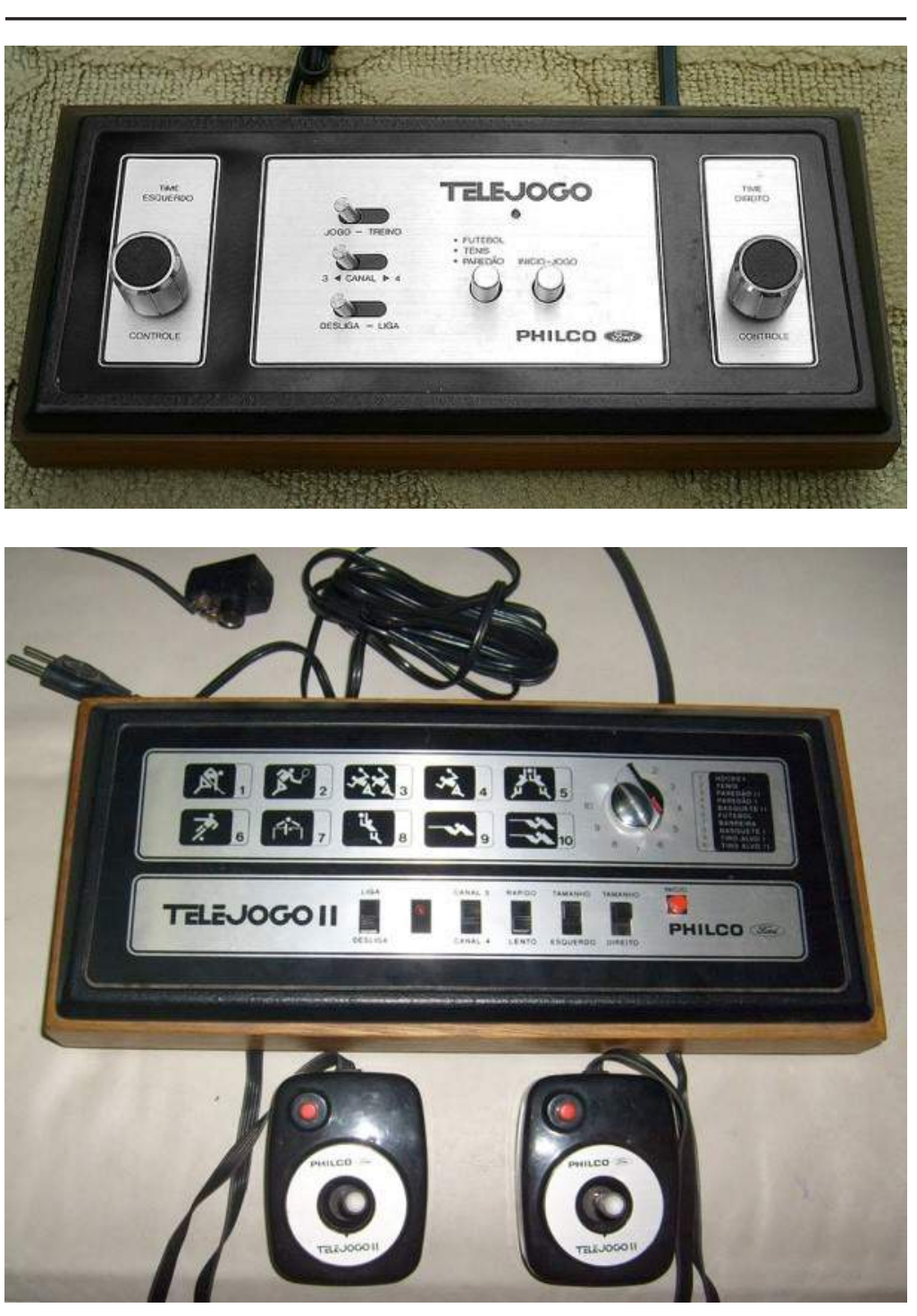

Figura 1: Telejogo e Telejogo II. Fonte: Mercado Livre.

Como a Reserva de Mercado impedia que empresas brasileiras importassem e distribuíssem o Atari 2600 norte-americano no país, algumas empresas criaram uma "solução" para essa política: trazer algumas unidades de Atari 2600 dos EUA por seus executivos ou engenheiros e tentar realizar o que é conhecido como "engenharia reversa" desses consoles, ou seja, a partir 
da análise dos componentes do equipamento original, partiu-se para a fabricação de consoles "compatíveis" com o Atari 2600 , com mistura de componentes nacionais e importados2. Esses consoles seriam chamados de clones. O primeiro clone de Atari 2600 lançado no Brasil foi o CX-2600, fabricado por uma empresa chamada "Atari Eletrônica Ltda.". O CX-2600 foi lançado em 1980, apenas três anos após o lançamento do Atari nos EUA (Chiado, 2013)

No entanto, antes que o mercado brasileiro pudesse ser abastecido com clones do console Atari 2600 algumas pequenas empresas eletrônicas brasileiras começaram a produzir cartuchos clonados para este console, uma vez que era muito mais barato e fácil fabricar cartuchos em comparação aos consoles. Este caminho também foi escolhido para atender a uma crescente base de usuários Atari 2600 no país, em sua maioria crianças e adolescentes das classes média e alta, cujos pais costumavam trazer o console Atari 2600 dos Esta-

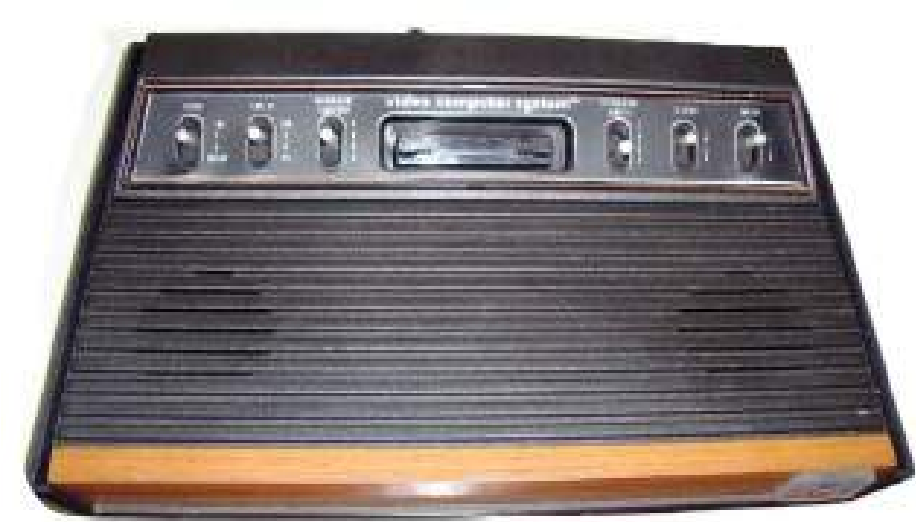

Figura 2: Video Computer System CX-2600. Fonte: Chiado (2013). dos Unidos, quando viajavam em negócios ou férias, por exemplo. Deste modo, abastecendo o mercado com cartuchos de jogos Atari (clones), essas empresas preencheram uma lacuna muito importante na recém-nascida "ecologia" de videogames brasileiros: a busca de novos títulos de jogos; se era possível às famílias mais ricas trazer um Atari 2600 do exterior, ainda era muito difícil comprar regularmente novos títulos de jogos, devido ao fato de o Atari 2600 não estar oficialmente no país. Havia, desta forma, um mercado exigente e crescente para os cartuchos Atari 2600, uma demanda à qual pequenas empresas responderiam rapidamente.

Um aspecto muito interessante da clonagem de cartuchos de jogos (e também a clonagem de consoles) foi o fato de alguns dos fabricantes apresentarem melhorias em relação aos cartuchos e consoles originais. Este é o caso, por exemplo, do fabricante de cartuchos Tron. Os cartuchos Atari 2600 produzidos por esta empresa possuíam um design único: uma "alça" superior que facilitava a remoção do cartucho do console, evitando assim danificar o cartucho ou o slot. Hoje em dia, este item é um dos cartuchos de Atari mais caros listados no Mercado Livre ${ }^{6}$, podendo custar, dependendo da condição de preservação do cartucho, muitas centenas de Reais.

\section{3: o Atari 2600 oficial e seus clones chegam ao Brasil}

Em 1983, várias empresas brasileiras estavam correndo contra o tempo - e umas contra as outras - para lançar seus próprios consoles compatíveis com o Atari 2600 (ou seja, clones). Todas essas empresas acreditavam que o novo aparelho eletrônico ultrapassaria a venda de outros produtos eletrônicos, como aparelhos de TV e som, no Natal de 1983. E eles não poderiam estar mais certos. Paralelamente, a Warner, proprietária da Atari, estava negociando com a Gradiente, uma empresa brasileira de eletrônicos, por meio de sua sub-

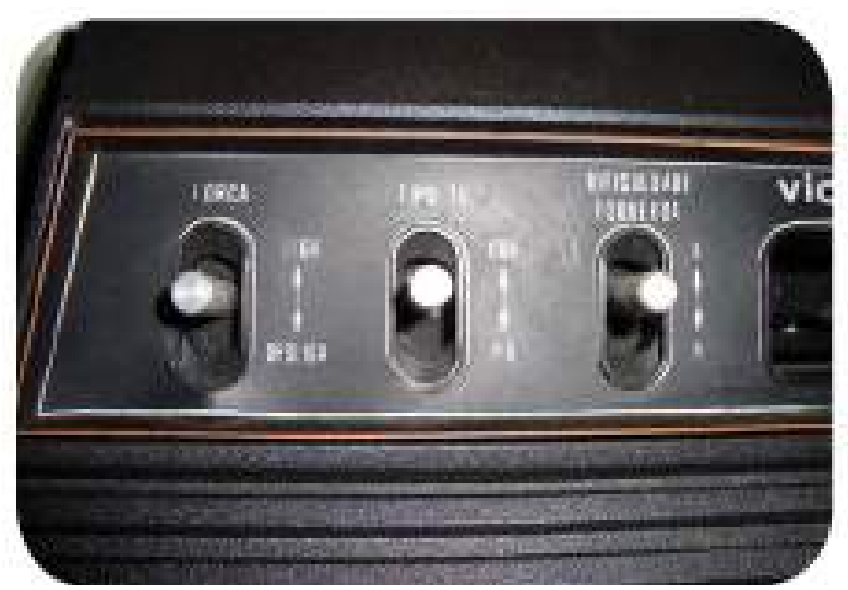

Figura 3: Video Computer System CX-2600, detalhe: Funções do painel traduzidas para o Português. Fonte: Chiado (2013).

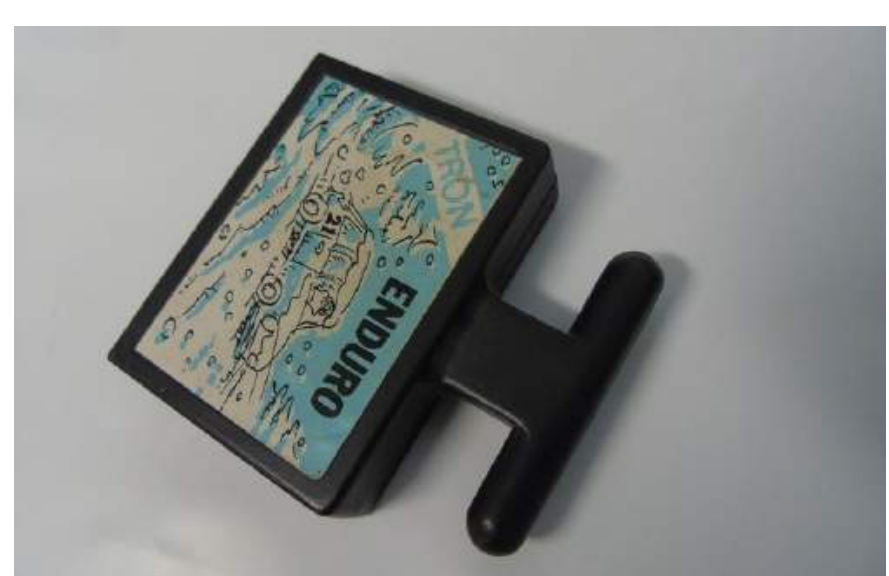

Figura 4: Cartucho Enduro Tron, com alça superior. Fonte: Mercado Livre.

75 PORTO ALEGRE | v. 22 | n. 38 | 2017 | p. $72-84$ Sessões do Imaginário 
sidiária Polyvox, o licenciamento e a produção do Atari 2600 no Brasil (contra todas as regras impostas pela Reserva de Mercado). Seria assim o "Atari oficial" a ser lançado no país. No entanto, os clones de Atari aproveitaram sua "liberdade" do Atari norte-americano e lançaram seus consoles apenas alguns meses antes que o Atari oficial pudesse chegar às lojas.

Como mencionado anteriormente, o primeiro clone de Atari 2600 lançado no Brasil foi o CX-2600, fabricado por uma empresa brasileira chamada Atari Eletrônica. Além do próprio console, a Atari Eletrônica também fabricou cartuchos clonados de Atari, para atender a uma crescente demanda de jogos, como mencionado anteriormente. Quando a Warner decidiu lançar o Atar 2600 no país, ela contatou o dono da Atari Eletrônica, o Sr. Joseph Maghrabi, um ex-empresário do ramo de joias, para estabelecer um acordo sobre o nome da empresa, já que a Warner não poderia iniciar as vendas do Atari no Brasil se já houvesse uma empresa com o mesmo nome e operando no mesmo negócio, o que era o caso. No final, um acordo foi feito entre o Sr. Maghrabi e a Warner, esta última permitindo que o primeiro continuasse a fabricar os cartuchos Atari 2600 "compatíveis" (Chiado, 2013).

Outro clone de Atari 2600 muito famoso foi lançado em 1983 no Brasil, também lançado antes do Atari 2600 oficial. Este clone foi fabricado por uma empresa sediada em São Paulo chamada Sayfi Computadores e foi chamado Dactari (TV Computer System - 2600-A). A produção inicial contou com 3000 unidades e foi vendida exclusivamente pela Computerland Store, também localizada em São Paulo. Tal como aconteceu com outros clones Atari, eles também usaram o processo de engenharia reversa para fabricar seu console. $O$ aspecto visual da Dactari foi tão parecido com o Atari oficial que o Sr. Julio Albertoni, CEO da Sayfi, disse em uma entrevista à edição 10 da revista Video News:

Desmontamos o Atari [oficial] e analisamos como funciona. Alguns componentes mandamos fazer aqui, os chips serão feitos por uma empresa americana. Nossa política é igual à dos japoneses: nada se cria, tudo se copia. Se deu certo com eles, por que não daria conosco? (Dactari, 1983, p. 64-65).

Além do Dactari, outro clone bem-sucedido de Atari 2600 foi o Dynavision, fabricado pela empresa Dynacom. De acordo com os sócios proprietários da Dynacom, o Dynavision era superior ao Atari 2600 original. Uma matéria publicada na edição 12 da revista Video Magia afirma:

Segundo o fabricante, embora inspirado no projeto do Atari VCS7, [o Dynavision] tem características muito superiores ao original. Exemplos: o material e o modelo empregados na produção dos joysticks são mais resistentes e com botão de disparos no topo do palito direcionador; a saída dos cabos do joystick é pela dianteira do console, evitando-se a dobra dos fios e a frequente quebra; a CPU (Unidade de Processamento) do console, do tipo 6502, idêntica à do famoso microcomputador Apple II que permite o acesso de até $64 \mathrm{~KB}$ de informações -, é muito mais poderosa que a empregada no Atari VCS (Jogomania, 1983, p. 11-14).

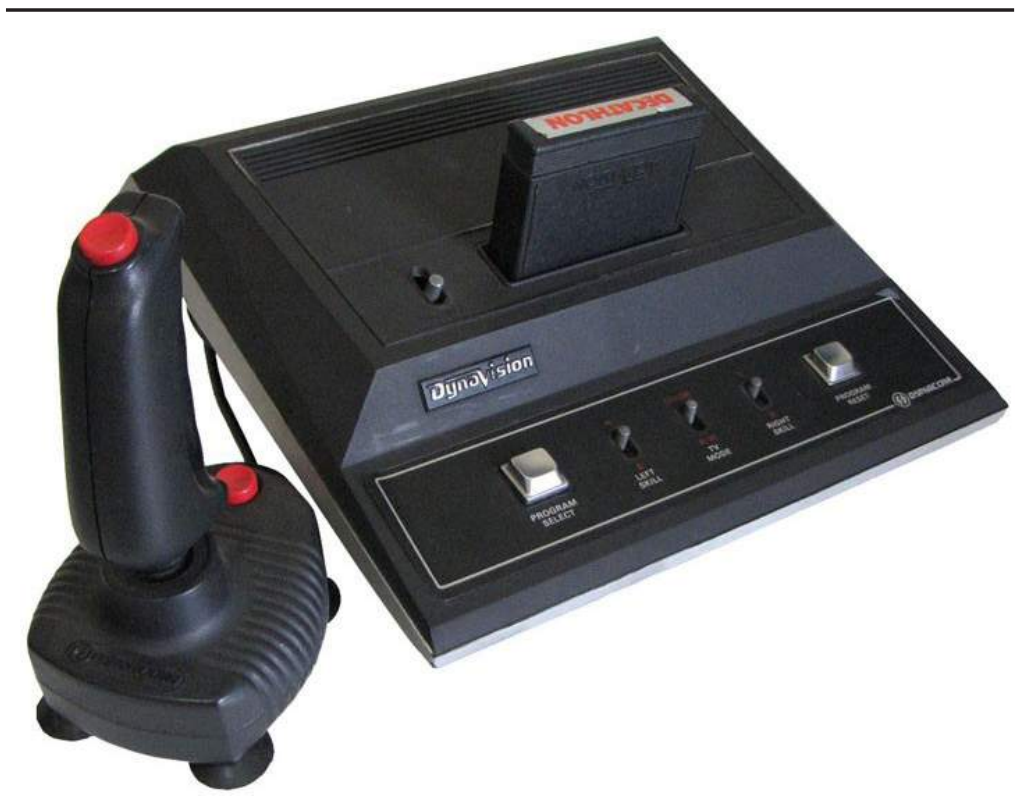

Figura 5: Console Dynavision, com controle ergonômico de dois botões.

Fonte: Wikipedia.

Também é importante mencionar outro clone de Atari 2600 bem-sucedido, o VJ-9000, fabricado pela Dismac, conhecida e respeitada empresa de calculadoras da época. Um fato interessante sobre a Dismac, no que tange ao Atari, é que a empresa também lançou clones de cartuchos, e esses clones tiveram seus títulos traduzidos para o português. Assim, títulos como Pitfall, Kaboom e Freeway seriam traduzidos para "Pantanal"; "TNT" (fazendo alusão ao próprio material explosivo) e "BR-101".

Não apenas as etiquetas e as caixas dos cartuchos eram traduzidas; algumas pequenas empresas que produziram cartuchos clonados também modificaram o código do software do jogo para substituir o nome do desenvolvedor/publisherporseusnomesouentãoremover completamente essas credenciais, buscando evitar questões jurídicas relacionadas à clonagem eà pirataria. 

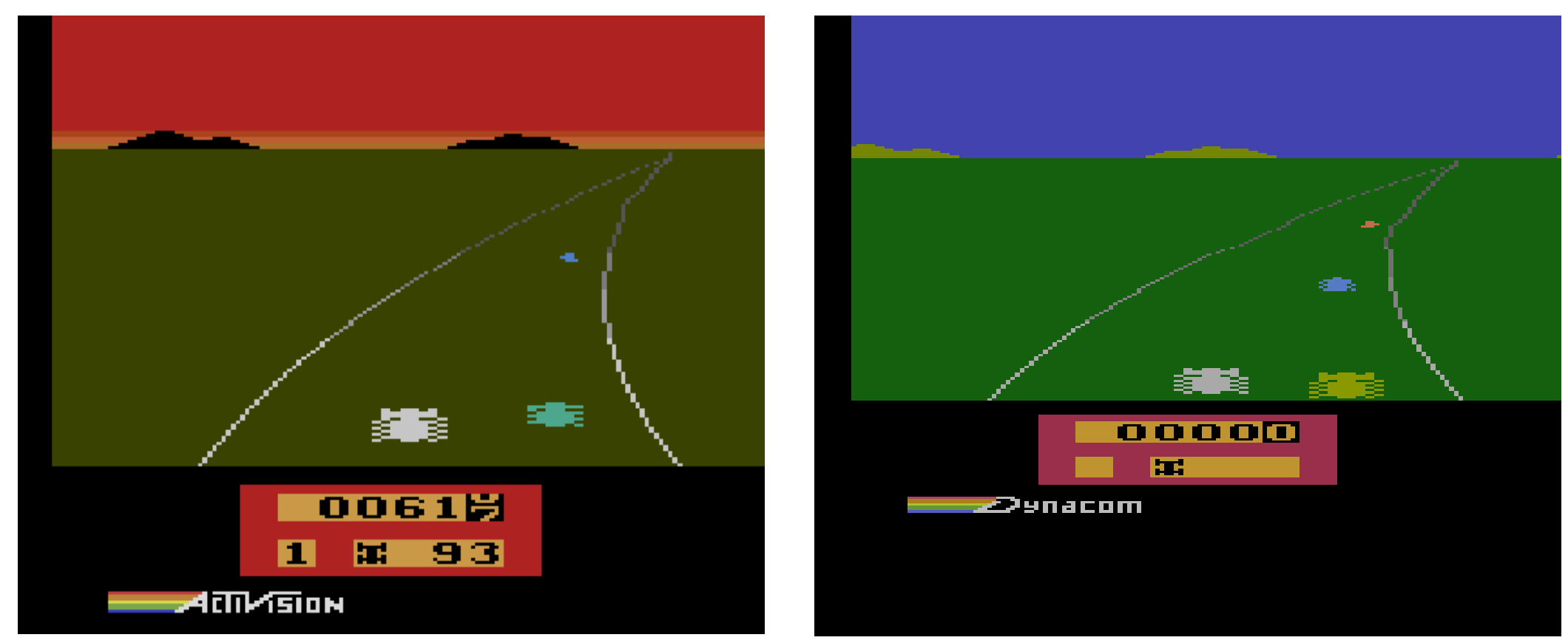

Figura 6: Esquerda: jogo Enduro original, Activision; Direita: Enduro, Dynacom. Fonte: Atari Mania.

Outros clones notáveis foram o CCE Supergame VG-2800', na verdade um clone do Coleco Gemini Norte-Americano, que assim como sua contraparte norte-americana também trazia conectores de joystick na parte frontal do console, e o Microdigital Onix Junior "estilo militar", que trazia um recurso inédito: um botão de pausa, algo que nenhum outro clone havia sequer tentado implementar.

Neste ínterim, a Polyvox adiava o lançamento do Atari 2600 "oficial" no país. No entanto, este atraso não parecia incomodar o gerente de marketing da empresa, Gilson Cardoso, que disse em entrevista a um jornal, em 9 de setembro de 1983: "A capacidade de produção dessas fábricas [fabricantes de clones] é pequena e não chega a afetar o desempenho previsto. Temos a maior rede de distribuição do Brasil e pode- mos oferecer nosso produto com garantia, o que essas fábricas não podem fazer" (Do Carmo, 1983, p. 25).

No final, com a ajuda de uma enorme campanha publicitária (aproximadamente 7 milhões de dólares), criada pela grande agência de publicidade DPZ, de Washington Olivetto e Gabriel Zellmeister (Pase, Tietzmann, 2017), o Atari oficial foi lançado pouco antes do feriado do Dia das Crianças. O slogan principal da campanha foi "O Atari da Atari", aludindo à sua qualidade supostamente superior em comparação com os vários clones disponíveis nas lojas. Também enfatizava a qualidade superior dos cartuchos Polyvox, com manuais e caixas belamente trabalhados.

Assim, com dezenas de pequenas e médias empresas de eletrônicos tentando vender seus consoles Atari, a "guerra dos clones" havia começado. Cada uma dessas empresas tentou entregar o melhor equipamento junto com o melhor preço, e também as melhores ofertas de cartuchos. Toda criança e adolescente queria ter um Atari em casa, não importava se fosse o Atari oficial ou um clone. O mais importante era fazer parte dessa nova cultura de entretenimento que estava começando a se formar no Brasil. De acordo com Chiado (2013), as vendas de Natal de 1983 foram enormes, graças ao novo "brinquedo" eletrônico chamado videogame, ou seja, o Atari oficial, licenciado pela Gradiente/Polyvox - apesar de todas as declarações da Reserva de Mercado, segundo as quais o licenciamento de uma tecnologia estrangeira era proibido - e seus muitos clones e, em menor medida, outros consoles como Odyssey e Intellivision. 


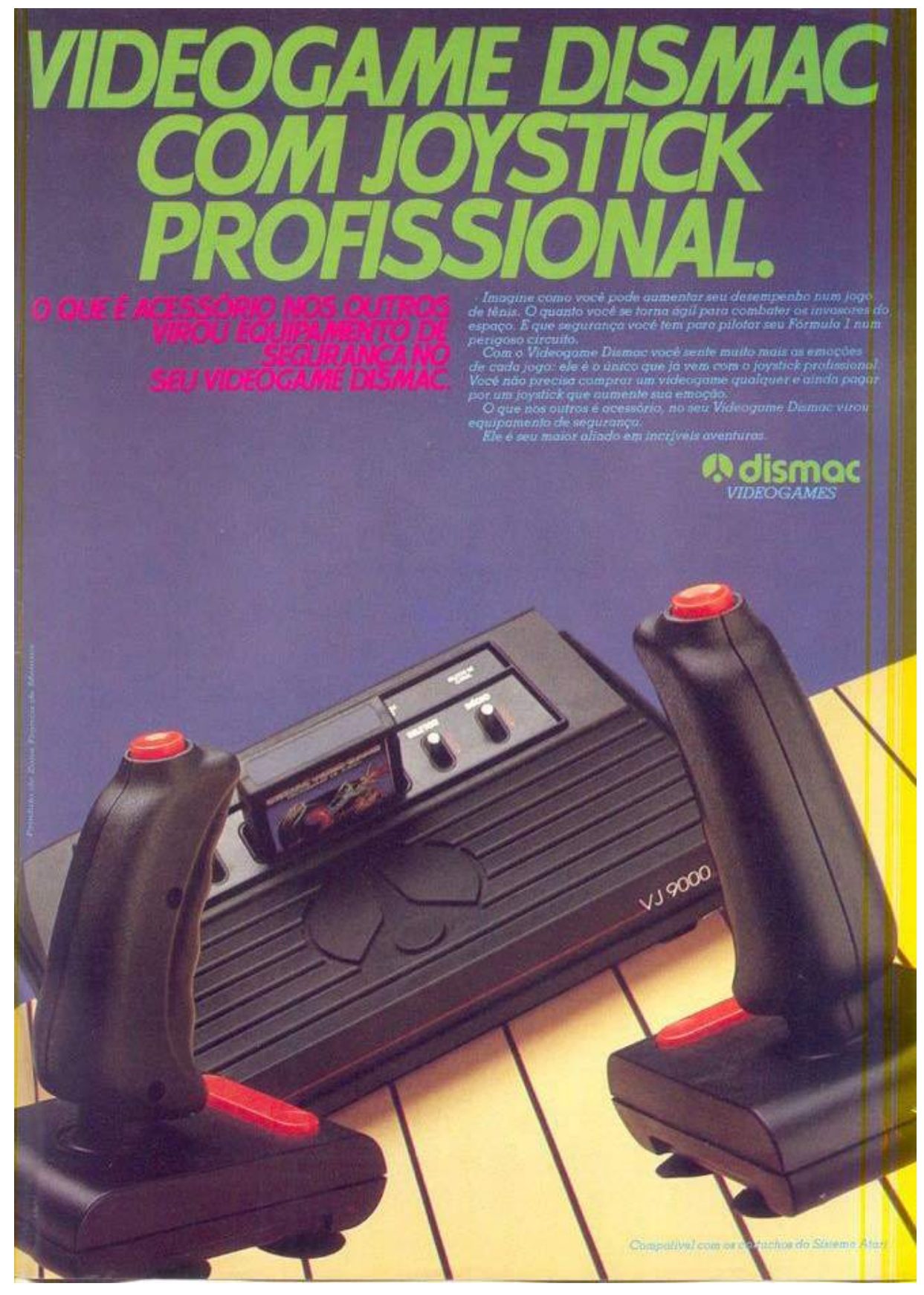

Figura 7: Propaganda do Dismac VJ-9000, enfatizando a qualidade superior de seu joystick.

Fonte: Atari Mania.
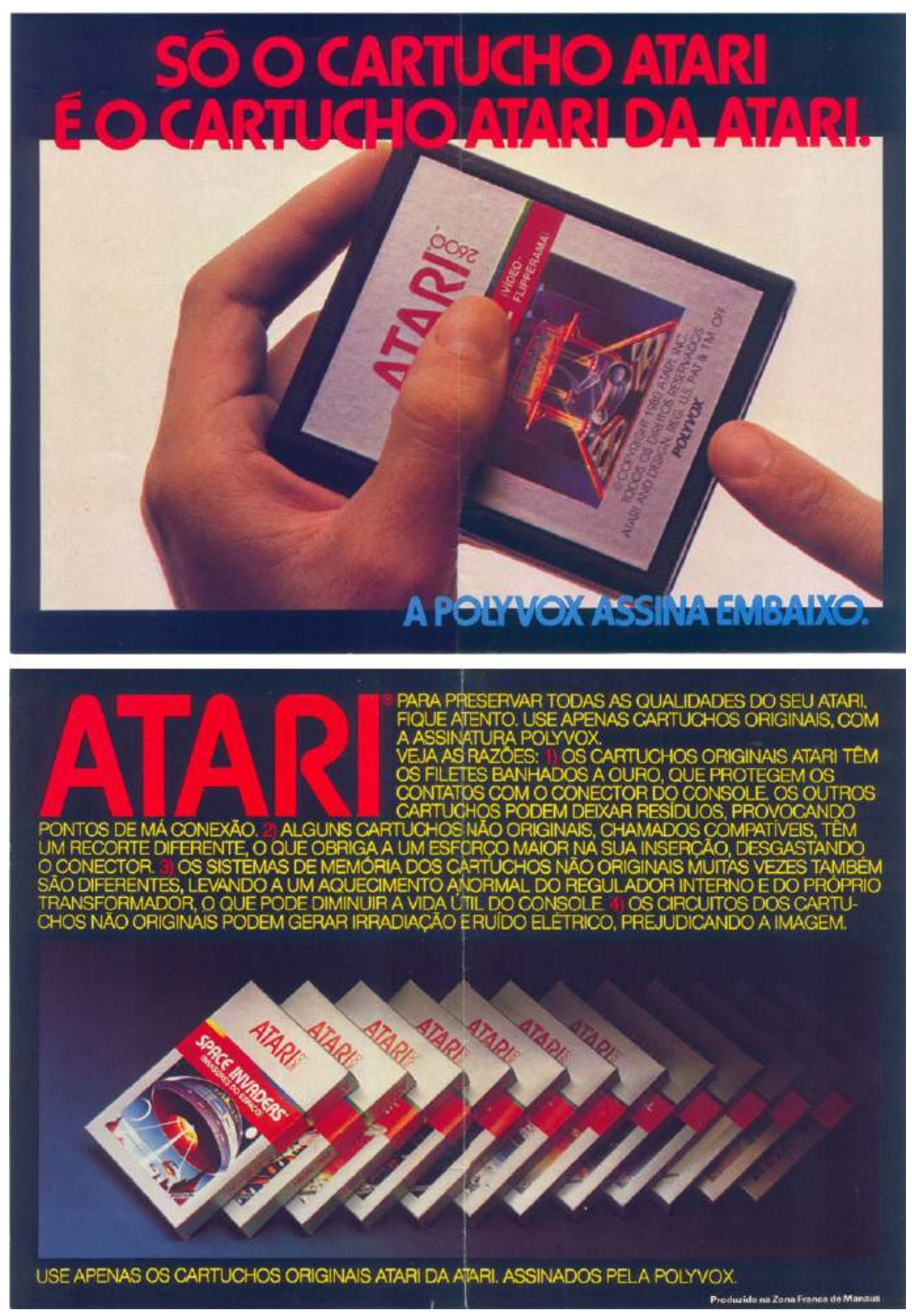

Figura 8: Propagandas de cartuchos oficiais da Atari, enfatizando a "originalidade" (e consequente superioridade) de seus produtos em relação aos clones ("compatíveis"). Fonte: Atari Mania. 


\section{5: a plataforma MSX e seus clones}

Dois anos após o lançamento do Atari 2600 no Brasil, bem como seus clones, as vendas da segunda geração de consoles (Atari 2600, Odyssey e Intellivision) começaram a cair no país, de forma semelhante ao ocorrido em 1983 no cenário norte-americano. Ao mesmo tempo, algumas empresas brasileiras de eletrônicos já haviam começado a clonar microcomputadores estrangeiros, como o Apple II, o Sinclair ZX Spectrum e a plataforma MSX. Uma vez que algumas dessas plataformas haviam experimentado sucesso com seus jogos em seus países de origem, jogos que eram superiores em termos de capacidades gráficas e sonoras em relação aos jogos do Atari, seus clones brasileiros seguiram na mesma linha. Na verdade, desenvolvedores de jogos como Ocean e Konami foram as responsáveis por muitos hits que tiveram início nestas plataformas, como Head Over Heels e a série Metal Gear, respectivamente. No Brasil, a Microdigital Eletrônica fabricou o clone do ZX Spectrum, chamado TK 90X; por sua vez, Gradiente - a mesma empresa que lançou o Atari 2600 no país - e Epcom (subsidiária brasileira da Sharp) lançaram clones de MSX, chamados Expert e Hotbit, respectivamente.

Ao contrário dos primeiros computadores IBM-PC (e compatíveis), os computadores MSX proporcionariam uso especial para a programação e execução de jogos. Isso aconteceu, em grande medida, devido à sua configuração de hardware e software, ou seja, à sua plataforma (Montfort, Bogost, 2009). Quase todos os computadores MSX contavam nativamente com conexões de áudio, vídeo e TV, portas para conexão de joysticks e slots de cartuchos, e vinham de fábrica com a linguagem de programação BASIC embutida em sua ROM, além de contar com a possibilidade de uso do MSX-DOS, um sistema operacional de disco muito semelhante ao MS-DOS dos IBM-PCs. Além disso, os primeiros computadores MSX vinham com pelo menos 16KB de memória de vídeo e podiam apresentar até 16 cores (o MSX2, sucessor do MSX, exibia até 512 cores). O chip de som utilizado no MSX, o Yamaha YM2149 (PSG), podia tocar três vozes simultâneas (canais), algo que nenhum IBM-PC da época poderia realizar. Tudo isso "empurrou" a plataforma de computador MSX para o domínio dos games. Além disso, como o MSX era originalmente um projeto japonês (com sistema operacional desenvolvido pela Microsoft norte-americana, o acima citado MSX-DOS), muitos desenvolvedores bem-sucedidos de hoje começaram a desenvolver seus jogos para o MSX, como é o caso da mais que conhecida Konami, desenvolvedora e publisher da série Metal Gear Solid, que teve seu início justamente na plataforma MSX, com o título Metal Gear, de 1987, criado pelo famoso game designer Hideo Kojima (também criador da série de jogos cyberpunk Snatcher, lançado para o MSX2 em 1988). Devido a todos esses motivos, e provavelmente porque os computadores MSX eram fabricados por empresas de eletrônicos bem conhecidas por seu público consumidor, como Sony, Sanyo, Panasonic, National, entre outras, a plataforma obteve grande respeito no Japão e em outras regiões que produziram o MSX, como é o caso de alguns países europeus - a Philips foi o principal fabricante e distribuidor da MSX na Europa.

Seguindo a mesma tendência, no Brasil, os computadores MSX também seriam fabricados por duas grandes e bem respeitadas empresas de eletrônicos, Gradiente e Sharp. Essas duas empresas já eram conhecidas por seus aparelhos de TV e áudio domésticos, e o lançamento de um computador (que também poderia atuar como um videogame) que poderia ser facilmente conectado aos periféricos da mesma marca (TVs, cassetes, aparelhos de som, etc.) era uma maneira natural de apelo ao público consumidor e de assim dominar rapidamente o jovem e crescente mercado nacional de computadores. Também é importante ressaltar que essas empresas investiram milhares de dólares em campanhas publicitárias em várias e diferentes mídias, como jornais, revistas, comerciais de rádio e TV.

Deste modo, a plataforma MSX acabou por se tornar um grande sucesso no Brasil, no que tange aos computadores domésticos de 8 bits. No entanto, esta história seria apenas outra história comum, se não fosse pelo fato de que tanto a Gradiente quanto a Sharp não tivessem permissão para produzir, distribuir e vender computadores com a marca MSX no Brasil, uma vez que não possuíam os direitos de licenciamento da MSX Association, proprietária da marca MSX à época. A falta de direitos legais ocorreu devido à mesma Política de Reserva de Mercado/Lei de Informática mencionada anteriormente. Como, então, a mesma Gradiente, sob a sua subsidiária Polyvox, conseguiu produzir, distribuir e vender o Atari oficial 2600 no Brasil e não a plataforma MSX? O fato é que, de acordo com alguns empresários dos anos 1980, a política de reserva de mercado funcionava apenas até "certo" ponto. Dependendo dos relacionamentos que a empresa $\mathrm{X}$ ou $\mathrm{Y}$ tivesse com o governo federal em dado momento, este permitiria que a empresa $X$ ou $Y$ explorasse um determinado mercado no país. Além disso, como na época não havia grande monitoramento de empresas estrangeiras para o que acontecia dentro do Brasil - em grande medida o próprio governo militar "blindava" o país dos olhares estrangeiros, às vezes era mais fácil e rápido partir para 
a clonagem do que esperar muitos meses ou até anos e ainda gastar milhares dólares aguardando um acordo comercial com empresas estrangeiras.

Como ocorreu com os cartuchos Atari, muitos jogos MSX clonados (cartuchos) também tiveram suas caixas e rótulos modificados, bem como seu código de software, pelo mesmo motivo: evitar problemas legais dos desenvolvedores e publishers de jogos, como é o caso dos jogos da Konami publicados pela Gradiente. Estas modificações acabaram por tornar tais jogos mais "amigáveis" aos jogadores brasileiros, já que muitas dessas versões tinham os menus traduzidos para o Português, assim como o material gráfico (caixas, encartes, manuais, etc.).

Embora muitos jogos MSX fossem encontrados na forma de cartucho, estes também eram disponibiliza-
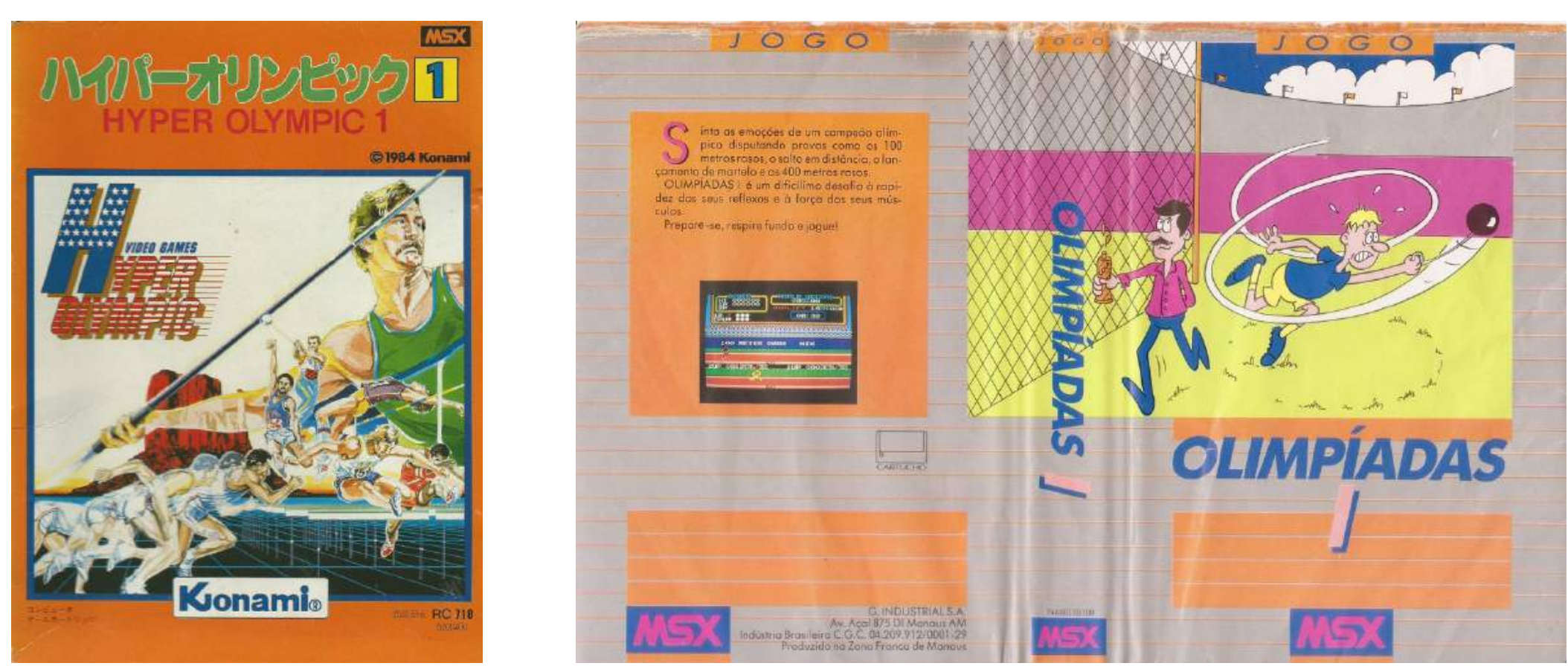

Figura 9: Esquerda: jogo Hyper Olympic 1, Konami; Direita: versão da Gradiente para o mesmo jogo, com título em Português, imagem modificada (com grande abordagem cômica) e nenhuma menção à desenvolvedora Konami.

Fonte: arquivo pessoal do autor.

dos na forma de fita cassete, já que a plataforma MSX trazia como configuração padrão uma conexão entre o computador e um gravador de áudio, algo comum com outros microcomputadores da década de 1980, como o Commodore 64 e o ZX Spectrum. Isso permitiu que jogos fossem vendidos a um preço mais baixo, mas também facilitou o ato de piratear esses jogos, já que era bastante fácil copiar o conteúdo de uma fita cassete, tão fácil quanto copiar uma fita de música. Deste modo, muitas empresas começaram a extrair os arquivos dos jogos dos cartuchos, o que é conhecido por ROM dumping, num primeiro momento em fitas cassete e, posteriormente, em disquetes. Como não havia nenhum dispositivo de proteção contra cópia naquela época, a proliferação de jogos piratas foi enorme. Também foi o início da proliferação de softhouses, "microempresas" (registradas ou não) que costumavam vender um pacote de jogos piratas (gravados em cassete ou em disquetes) por um preço fixo. Em pouco tempo, estes pequenos espaços seriam tomados por jovens proprietários de computadores de tais plataformas que passavam tardes inteiras nas softhouses, assistindo aos novos "lançamentos", conversando com os vendedores e, eventualmente, comprando alguns jogos para jogar em casa.

A "penetração" de tais práticas possibilitou aos proprietários brasileiros de MSX, numa era pré-globalização e pré-Internet, obter acesso antecipado a títulos que acabavam de ser lançados no exterior. Posso citar, como exemplo próprio, meu primeiro contato com o jogo Knightmare, desenvolvido pela Konami para o sistema MSX, que ocorreu no mesmo ano do seu lançamento no Japão, 1986. Certamente se não fosse pelas práticas de clonagem e pirataria, não teria conhecido este jogo tão rapidamente - talvez um dos mais importantes jogos que moldariam minha vida como jogador e pesquisador de videogames. Para fins de comparação, consegui adquirir a versão original de Knighmare - completo, com cartucho, caixa e manual - apenas no ano de 2011, via MercadoLivre.

No que tange aos computadores clássicos e aos jogos retrô, a plataforma MSX possui uma das comunidades mais importantes e ativas do Brasil. A lista de discussão MSXBR-L, fundada em 1995, é a maior comunidade de usuários e fãs de MSX no País, com centenas de e-mails trocados a cada mês. A plataforma também foi uma das primeiras a fornecer acesso à programação de jogos para jovens brasileiros naquela década.

80 PORTO ALEGRE | v. 22 | n. 38 | 2017 | p. $72-84$ Sessões do Imaginário 


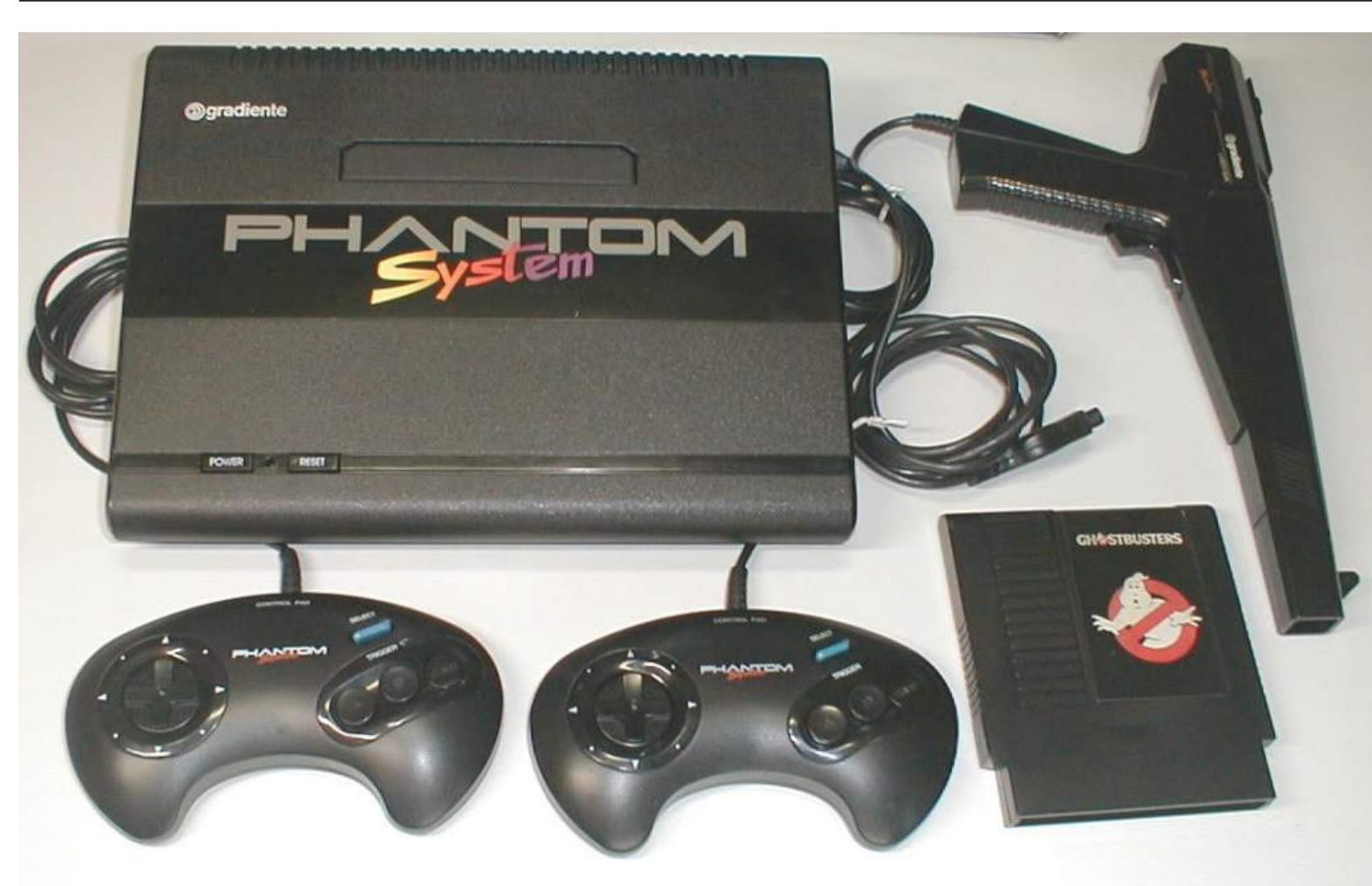

Figura 10: Phantom System, com seus 2 controles, pistola de luz e o cartucho que vinha com o console: Ghostbusters.

Fonte: Mercado Livre.

\section{9: a plataforma NES e seus clones}

Com o lançamento da plataforma NES em 1985 na América do Norte, os consoles de videogames retornariam do "limbo" de dois anos, após o crash de 1983. Como o Brasil ainda estava sob a jurisdição da Reserva de Mercado, a prática de clonagem continuava sendo executada. Entre 1988 e 1989, várias empresas brasileiras começaram a fabricar seus clones NES, compatíveis ou com o sistema americano ou com o sistema japonês (cartuchos de 72 ou 60 pinos, respectivamente).
Talvez o clone NES mais notável lançado no Brasil tenha sido o Phantom System, fabricado pela Gradiente (a mesma empresa que lançou o Atari oficial e o clone de MSX Expert). Segundo Chiado (2016), no final da década de 1980, a Gradiente deveria lançar oficialmente o Atari 7800 no Brasil, mas o acordo com a Atari Norte-Americana não foi realizado. Tendo observado o sucesso recente do NES em todo o mundo e junto a isso a dificuldade de se negociar com a Nintendo Japonesa para tentar lançar oficialmente o NES no Brasil, a Gradien- te optou por clonar o console japonês (Chiado, 2016). Aproveitando o desenvolvimento já iniciado da "carcaça" para o que seria a versão nacional do Atari 7800, a Gradiente optou por utilizar a mesma carcaça para seu clone de NES. Ao final, o Phantom System acabou com aspecto visual muito semelhante ao Atari 7800 norte-americano. Além disso, a empresa aproveitou o mesmo design do controle do SEGA Mega Drive no controle do Phantom System, talvez um dos clones brasileiros de NES mais conhecidos até de os dias hoje.

É importante ressaltar que o Phantom System era totalmente compatível com a versão norte-americana do NES, ou seja, permitia que os cartuchos de 72 pinos fossem usados normalmente. No entanto, seus controles usariam o mesmo tipo de conexão usado pelo Atari 2600 e a plataforma de computador MSX (conexão DB-9) e por isso não era compatível com os controles originais do NES.

Outro clone de NES lançado no Brasil foi o Dynavision II, fabricado pela mesma empresa que produziu um dos clones Atari 2600 (o Dynavision, da Dynacom). O Dynavision II permitia a utilização de cartuchos Nintendo de 60 pinos, por isso era diretamente compatível com cartuchos japoneses do Famicom. No entanto, não era necessário importar cartuchos do Japão, uma vez que a Dynacom (e outras empresas) também fabricavam cartuchos de 60 pinos, e também era possível usar um adaptador de 72 a 60 pinos para usar cartuchos do NES americano ou clones brasileiros, como os cartuchos do sistema Phantom System.

Tal como aconteceu com os cartuchos clonados de Atari 2600 e MSX, os fabricantes de brasileiros de cartuchos NES também traduziram seus rótulos e caixas, bem como substituíram conteúdos in-game, para evi- 
tar problemas com desenvolvedores e/ou publishers de jogos. Um excelente exemplo é o clássico Super Mario Bros.: fabricantes brasileiros costumavam mudar artes de rótulos e caixas, traduzir títulos e também retirar referências aos desenvolvedores e publishers originais. A versão produzida pela Gradiente teve seu título (rótulo e caixa) traduzido para Super Irmãos. Na tela inicial, de menu, a empresa retirou o título do jogo, Super Mario Bros., deixando apenas as opções de número de jogadores. Outra empresa a produzir clone do mesmo jogo, a Dismac, traduziu o título do jogo para Super Mário (com acento agudo na letra $A$; acento este que não existe no título original). Na tela de abertura, a Dismac substituiu o título do jogo por uma imagem do personagem, imagem esta originalmente presente noutro clone (provavelmente de origem chinesa) do mesmo jogo.

Conforme apontado anteriormente, a década de 1990 veria o fim da Reserva de Mercado/Lei de Informática, fato que ficou conhecido como "abertura do mercado". Neste novo cenário político e econômico, empresas estrangeiras como Nintendo, SEGA e Sony dominariam o mercado brasileiro de videogames (em consoles de videogames) e a era da clonagem chegaria ao fim. Em 1993, a Playtronic, outra subsidiária da Gradiente, lançaria oficialmente o Super Nintendo no Brasil (apenas dois anos e meio após seu lançamento no Japão). Em 1997, a mesma Playtronic distribuiria o Nintendo 64 no país. Por outro lado, uma vez que a importação de bens agora era permitida, o console Sony Playstation poderia ser encontrado em diversas lojas de informática do país. Com o início da era do CD nos videogames, um novo ciclo de pirataria começaria em breve no país.
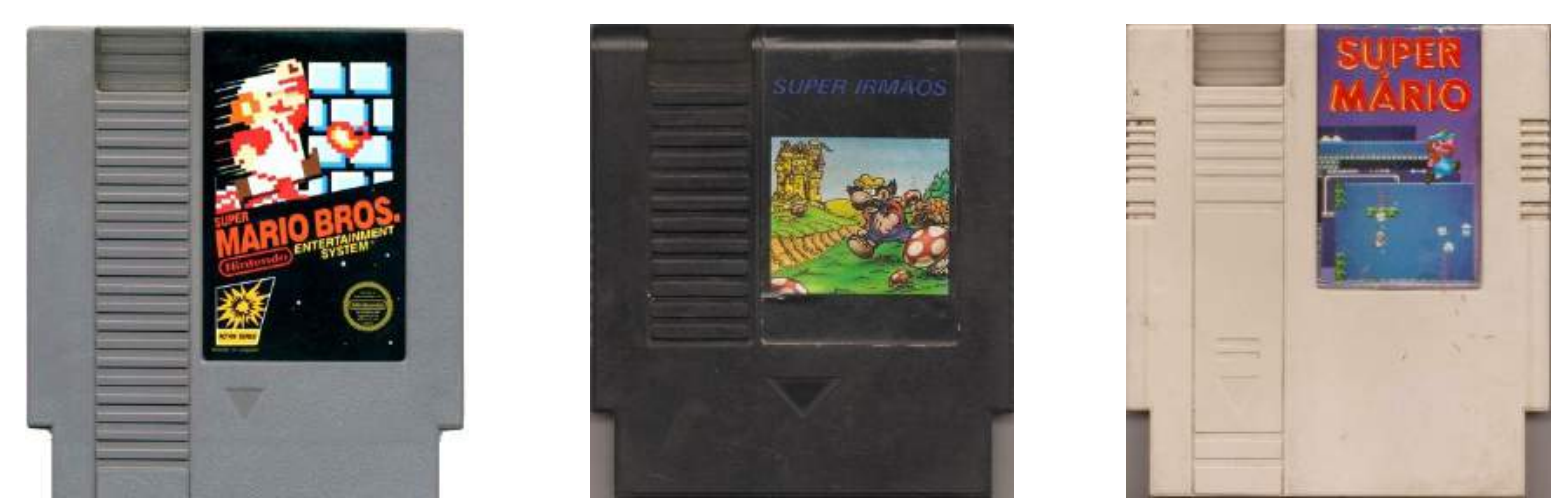

Figura 11: Esquerda: Super Mario Bros. original (Nintendo); Centro: Super Irmãos (Gradiente/Phantom System); Direita: Super Mário (Dismac).

Fonte: arquivo pessoal do autor.
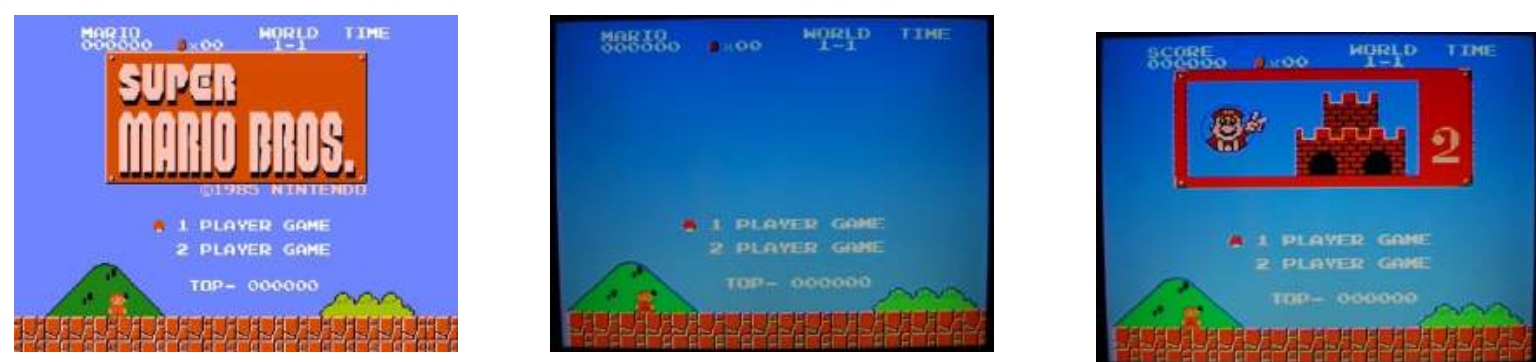

Figura 12: Esquerda: tela de abertura de Super Mario Bros. original (Nintendo) Centro: tela de abertura de Super Irmãos (Gradiente/Phantom System) com título do jogo logo extraído; Direita: tela de abertura de Super Mário (Dismac), com o título do jogo alterado. Fonte: arquivo pessoal do autor. 
Considerações finais: clonagem e pirataria como fatores-chave para o estabelecimento de mercado incipiente de videogames na década de 1980 no Brasil

A complicada situação econômica e política no Brasil, durante a década de 1980, favoreceu a proliferação de consoles de videogames no país, através de seus clones, apesar da Política de Reserva de Mercado; na verdade, muito "por causa" dela. A "criatividade" brasileira e também um certo ethos, aquilo que muitos chamam de "jeitinho Brasileiro", contribuíram para a disseminação de consoles de videogames no país, alguns deles com melhorias em seus recursos.

Isso permitiu ao público brasileiro ter contato com consoles de videogames relativamente cedo, tendo em vista as dificuldades enfrentadas numa era anterior à globalização e à Internet, o que levou ao que eu chamo de início de uma cultura de videogames no país. Se não fosse pelos clones e pela pirataria de jogos, essa cultura começaria, acredito, pelo menos uma década depois.

Dentre alguns aspectos que poderiam apontar para uma emergente cultura de videogames no Brasil, ainda no início da década de 1980, poderíamos relacionar:

- Conhecimento de títulos e desenvolvedoras de videogames:

* Além dos jogos para Atari 2600, os usuários de consoles e microcomputadores dos anos 1980 tiveram acesso rápido a títulos de jogos que acabavam de ser lançados em seus países de origem, como Double Dragon e Metal Gear, além de desenvolvedoras como Taito e Konami, através dos jogos desenvolvidos para NES e MSX, por exemplo. Este conhecimento era ainda reforçado pela grande quantidade de publicações destinadas aos jogos e à computação pessoal, como as revistas MSX Micro, CPU MSX, INPUT, entre outras, que destinavam grande parte de seu conteúdo à divulgação e reviews de lançamentos de títulos, assim como à programação de jogos.

- Conhecimento de características, gêneros e mecânicas empregadas em videogames:

* Pela primeira vez os usuários de consoles e microcomputadores tiveram acesso a diversos gêneros de jogos e assim puderam experimentar e conhecer mecânicas distintas neles empregadas, como jogos de plataforma (Donkey Kong, Super Mario Bros.), side-scrollings (Pitfall, Double Dragon), shoot'em-ups (Space Invaders, Knightmare), adventures (Angra, jogo nacional desenvolvido para MSX), esportes (Decathlon, Track'n Field), etc.

\section{- Campeonatos de videogames:}

* Várias empresas e organizações brasileiras, como SESC, organizavam campeonatos de videogames, desde a era do Atari 2600. Estas competições eram divulgadas pela grande mídia e reuniam dezenas e centenas de competidores em torno de um mesmo título.

\section{- Clubes de videogames:}

* Semelhantes às vídeo-locadoras da época, os clubes de videogames possibilitavam que seus sócios alugassem jogos mediante pagamento de uma quantia fixa mensal; desta forma, os proprietários de consoles não ficavam restritos aos títulos disponíveis no mercado nacional, já que muitos destes clubes tinham acesso a títulos ainda inéditos no Brasil.

- Negociação e troca (pirataria) de jogos:
* Mais comum entre proprietários de microcomputadores, a prática de venda de jogos (piratas) certamente proporcionou uma grande expansão do acesso a títulos diversos. Como os jogos eram copiados (em fita cassete ou disquete), o valor unitário era bem inferior ao preço de um jogo de console (em cartucho), o que tornava mais fácil a obtenção de grande quantidade de títulos, que poderiam então ser experimentados e avaliados por seus usuários, que construíam grandes bibliotecas de jogos.

Estes são apenas alguns aspectos que, ao meu ver, contribuíram para que o mercado (formal ou informal) de games no Brasil pudesse se estabelecer ainda no final dos anos 1980, início dos anos 1990. Deste modo, este trabalho buscou desenvolver a hipótese de que sem as práticas de clonagem e pirataria de videogames que ocorreram ao longo da década de 1980, justamente por causa das restrições impostas pela Reserva de Mercado, os brasileiros teriam tido ao menos uma década de atraso antes que pudessem ter amplo contato com a grande ecologia dos jogos eletrônicos.

Como aponta Zielinski (2006), parece bastante importante "cavar" cada vez mais profundamente determinado período de tempo de uma determinada mídia, procurando trilhas e traços desconhecidos, não observados, esquecidos, que foram deixados de lado ou para trás, se o que se quer é entender melhor determinada mídia e sua relação com os diversos aspectos culturais, econômicos e sociais que sempre rodeiam qualquer fenômeno de mídia; sobretudo os videogames, este (ainda) jovem objeto novo-midiático. 


\section{Referências}

ATARI MANIA. Disponível em: <http://www.atarimania. com/>. Acesso em: 15 jul. 2017.

CHIADO, M. 1983: o ano dos videogames no Brasil. São Paulo: Edição do autor, 2013.

DACTARI. In: Video News No 10. São Paulo: Sigla, 1983.

DO CARMO, João. "O Atari da Polyvox já está pronto". In: Folha de São Paulo, ed. 7/9/1983. São Paulo: Grupo Folha, 1983.

HUHTAMO, E; PARIKKA, J. Media Archeology. Oakland: Univ. of California Press, 2011.

IKEHARA, H. A reserva de mercado de informática no Brasil e seus resultados. In: Akropolis. Vol. 5, N¹8, 1997.

JOGOMANIA. In: Videomagia No 12. Rio de Janeiro: Editora Semente, 1983.

MARQUES, I. Reserva de Mercado: um mal entendido caso político-tecnológico de sucesso democrático e fracasso autoritário. In: Revista de Economia, vol. 24. Curitiba: UFPR, 2000.

MERCADO LIVRE. Disponível em: <http://www. mercadolivre.com.br/>. Acesso em: 15 dez. 2017.

MONTFORT, Nick; BOGOST, lan. Racing the Beam: The Atari Video Computer System. Cambridge/MA: MIT Press, 2009.
OLIVEIRA, S. A crise Financeira dos anos 80. CMI Brasil: Centro de Mídia Independente. 26 fev. 2005. Disponível em: <http://www.midiaindependente.org/pt/ blue/2005/02/308819.shtml>. Acesso em: 15 dez. 2017.

PASE, André Fagundes; TIETZMANN, Roberto. Man's Best Enemy: The Role of Advertising During Atari's Launch in Brazil in 1983. Kinephanos: revue d'études des médias et de culture populaire. v. 7, nov. 2017. Disponível em: <http://www.kinephanos.ca/Revue_files/2017_Pase_ Tietzmann.pdf>. Acesso em: 8 dez. 2017.

PLANALTO. Lei 7232, de 29 de Outubro de 1984. Disponível em: <http://www.planalto.gov.br/ccivil_03/ leis/L7232.htm.> Acesso em: 15 jul. 2017.

WIKIPEDIA. Disponível em: <wWw.wikipedia.com> Acesso em: 20 fev. 2018.

ZIELINSKI, S. Arqueologia da Mídia. São Paulo: Annablume, 2006.

\section{Notas}

1 Trabalho apresentado no GP Games, XVII Encontro dos Grupos de Pesquisas em Comunicação, evento componente do $40^{\circ}$ Congresso Brasileiro de Ciências da Comunicação.

2 Doutor em Comunicação pela Universidade Federal do Rio de Janeiro (2012). Mestre em Comunicação pela Universidade Federal do Rio de Janeiro (2006). Professor do Programa de Pós-Graduação em Mídia e Cotidiano da Universidade Federal Fluminense (Universidade Federal Fluminense, Centro de Estudos Gerais, Instituto de Artes e Comunicação Social. Rua Professor
Lara Vilela 126. São Domingos. 24210590 - Niterói, RJ Brasil). E-mail: emmanoferreira@midia.uff.br.

3 Disponível em: <http://www.planalto.gov.br/ccivil_03/ leis/L7232.htm>. Acesso em: 15 jul. 2017.

4 Muitas das empresas que desenvolveram clones acabaram adquirindo os componentes necessários ("importados") através de meios ilegais (como, por exemplo, através de contrabando do Paraguai) ou através de brechas legais na Reserva de Mercado.

5 Durante a Reserva de Mercado algumas empresas brasileiras foram registradas de forma homônima a empresas estrangeiras já estabelecidas, a fim de obter alguma atenção do público em geral, que era, por assim dizer, "enganado". Este foi o caso da Sharp, fabricante de um dos modelos brasileiros de MSX. Neste caso em particular, a companhia homônima japonesa acabou por firmar uma parceria com a empresa brasileira.

6 Disponível: <http://www.mercadolivre.com.br/>.

7 Antes de ser chamado de Atari 2600, o nome do console era Atari VCS (Video Computer System).

8 Assim como Gradiente, a empresa que licenciou o Atari 2600 no Brasil, a CCE também foi uma empresa de eletrônicos bem conhecida em todo o país, reconhecida pelos seus aparelhos de TV e som com preços mais populares. 